\title{
Young Learners' Perceptions of Learning English Using Language Games in a Non - Formal Context
}

\author{
Assoc. Prof. Dr. Tengku Nor Rizan Tengku Mohamad Maasum \\ Assoc. Prof. Dr. Rosniah Mustaffa \\ Prof. Dr. Siti Hamin Stapa \\ School of Language Studies \& Linguistics, \\ Faculty of Social Sciences \& Humanities, Universiti Kebangsaan Malaysia
}

Doi:10.5901/mjss.2015.v6n6s5p375

\begin{abstract}
In Malaysian schools where English is taught as a second language, the need to maximize learners' exposure to the language outside the classroom is vital. Learning is greatly enhanced, especially among young learners through exposure to English media and language learning activities. However, learners in rural primary schools have very limited exposure to English media and hardly ever use English outside the classroom despite constant encouragement from teachers. They also refrain from participating in English class activities because of a lack of motivation and self-confidence. This paper reports on a possible initiative that may address this need of young rural learners. Forty BA English Language Studies $3^{\text {rd }}$ year undergraduates enrolled in a course that required them to create language games as their final class project. A rural school was selected to execute the pilot project in an informal classroom setting. Acting as facilitators to 112 students all aged 9 years, these undergraduates engaged the pupils in language games that they had created, taking into account the learners' age, English proficiency and interests. Pupils were observed to become less inhibited in the company of these young facilitators in a nonthreatening, informal environment. The project offered opportunities for the student facilitators and their young learners to interact. At the end of the session, the learners were asked to respond to a self-report questionnaire to provide feedback about their perception of the games and the facilitators involved. The encouraging results are good reason for continuing such engagements between undergraduates and pupils.
\end{abstract}

Keywords: language games, language learning, non-threatening approach, facilitators, second language

\section{Introduction}

Learning a second language is admittedly a complex and challenging endeavour, and numerous reasons have been given to explain why Malaysian ESL/EFL learners, especially those in the rural areas, fail to learn English to any appreciable level of proficiency. Factors such as poor learning approaches, lack of confidence and motivation, negative perceptions of English as a foreign language, or unsuitable teaching methods/approaches, and the syllabus are widely acknowledged as valid reasons. One of the most important factors is most likely that these learners lack exposure and opportunity to use the language in natural settings (Samuel \& Zaitun Bakar, 2008).

From informal conversations with schoolchildren, it was found that they refrained from speaking English whether in or out of class for fear that their poor speaking ability would cause them to be perceived as slow or incompetent learners. Even with constant encouragement from their teachers, the lack of confidence and the fear of making mistakes hold them back. This was the same finding from a study with university students in Laos (Souriyavongsa et al., 2013).

In Malaysia, the problem is compounded by the fact that pupils come from different ethnic groups and so they tend to use their own dialect/language to interact among themselves simply because it feels more comfortable to them. English is largely perceived as a foreign language for which they do not have much use other than in English class. This is markedly true in the case of schoolchildren in the rural areas as their contact with English is only during their English classes in school (Normazidah Che Musa et al., 2012). In addition, they tend to lack support to use English at home and in the community, and inevitably have inadequate or insufficient exposure to the language in their rural environment. With such limited exposure and little opportunity to construct their own understandings, it is unsurprising that learners frequently become disengaged.

As ESL pupils in rural schools have little motivation to learn English, their teachers find it even more challenging to 
engage their interest in learning. The language games project reported in this paper emerged from a discussion about a group project for a cohort of English Language Studies (ELS) undergraduates at the Universiti Kebangsaan Malaysia. When the undergraduates were asked to think about using the project to help schoolchildren get more opportunities to use English, they suggested that a good strategy might be to encourage them from very young to participate in activities that necessitate using English so that it becomes an automatic second language, spoken confidently, without any fear of embarrassment. Further discussion led to the idea of initiating a community English-literacy programme with a selected primary school. The language games project grew out of that idea; it was suggested as a non-threatening approach to get young learners to use English. This approach supplements the existing repertoire of tools that ESL teachers might already have, such as worksheets, music and songs, and simple computer games.

The challenge then was for the ELS undergraduates to devise games that require team work and interaction, and equally important, the use of English among the pupils to achieve the goals of the game. One important goal of the game, besides creating an opportunity for movement and oral interaction, is to offer the opportunity to really use the language without reserve. In other words, while some important new vocabulary and expressions are introduced as part of the game, pupils are to use whatever little English they can muster to participate. Still, for practical reasons and for continued support, teachers need to prove to the school authorities the real effect on learning these language games have on pupils's motivation to learn, as well as on measurable outcomes such as reading and writing ability and accuracy in language use. It is also important to have clearly stated objectives and learning goals for each game so that pupils' learning may be assessed after some time.

Since the proof of the pudding is in the eating, one important way to evaluate the programme is to obtain feedback from the very learners who have experienced the game or activity. Obtaining feedback from the primary stakeholders is an important aspect of this project; it conveys to the young learners that their opinions matter, and that their participation in learning is taken very seriously. This is part of what the learner-centred classroom is about.

The aim of this paper is to describe the language learning games project that was piloted in a rural school, and to discuss the feedback from the young participants themselves about their experience. It is necessary first of all to provide a glimpse of the educational setting that is the backdrop to ELT in Malaysian primary schools. A brief review of the literature on using language games in ELT is also necessary to establish the theoretical basis and pedagogical significance of the project before the feedback data is discussed.

\section{The Malaysian English Curriculum for Primary Schools}

In Malaysia, the Primary School Standard Curriculum (KSSR) was introduced as an effort to restructure and enhance the existing curriculum to ensure that pupils acquire the appropriate knowledge, skills and values to face the challenges of the 21st century. Level I (Year 1, 2 \& 3) of the Primary School Standard Curriculum started in 2010/2011 while Level II for Years 4, 5 \& 6 started in 2014. KSSR is based on a statement of standards which encompasses content standards and learning standards to be achieved by a pupil in a specific period and level of schooling. Content standards are specific statements on what the pupils should know and can do, within a specific period of schooling, covering the areas of knowledge, skills and values. Learning Standards are set criteria or indicators of education quality and achievements which can be quantified for each content standard.

This curriculum focuses on the 4Rs - the four basic skills of Reading, Writing, Arithmetic and Reasoning and it is designed to cater to six areas of development:

- Communication

- Spirituality, Attitude and Values

- Humanitarian

- Physical and Aesthetic Development

- Science and Technology (http://www.moe.gov.my/v/soalan-lazim-view?id=146\&cat=30\&keyword=\&page=1\&)

According to the Assistant Director of the Educational Technology Division, Ministry of Education, the Standard Curriculum uses diverse approaches in teaching and learning including hands-on learning, using games and projects and learning outside the classroom (http://www.slideshare.net/Fadzliaton/transformasi-kurikulum-kssr7171559?utm_source= slideshow02\&utm_medium=ssemail\&utm_campaign=share_slideshow_loggedout).

English is taught formally as a subject in national schools for a total of 5 hours per week. Other than that, there is no other subject that uses English as a medium of instruction. Perhaps this is where the fundamental problem in the Malaysian ESL situation lies: there seems little reason for pupils to attend to English as it is not used beyond the few 
lessons allotted to the subject. Hence the continual challenge in "promoting" English to pupils and "enticing" them to use it through the use of fun activities.

\section{Language Games in ELT: Theoretical Perspectives}

According to interactionist second language acquisition (SLA) theories reflecting Krashen's theory (1994), comprehensible input is critical for second language acquisition, and interaction can enhance second language acquisition and fluency. In fact, two-way interaction is critical in learning a second language (Pica, 1996). However, the role of interaction in second language acquisition (SLA) is valued quite differently by different theorists. For Krashen $(1985,1994)$, whose theory became a predominant influence in both second language teaching practice and later theories, interaction must consist of "comprehensible input" (Krashen, 1985, 1994), which means that the message can be understood at the level just beyond the current linguistic competence of learners (Krashen, 1996) as well as "output" (Swain, 1995), which provides opportunities for independent expression and negotiation of meaning. Krashen's scaffolding theory, referred to as $i+1$, is similar to Vygotsky's "zone of proximal development" (1962). Viewed as an innatist perspective, it maintains that a second language is acquired unconsciously in a manner similar to the acquisition of a first language. Language input can be made comprehensible using a variety of strategies, such as linguistic simplification, and the use of realia, visuals, pictures, graphic organizers, and other current ESOL strategies.

While Krashen (1994) states that only one-way comprehensible input is required for SLA, others, acknowledging the role of two-way interaction, take an interactionist position. Pica (1994), Long (1985), and others assert that conversational interaction facilitates SLA under certain conditions. Lightbrown and Spada (1999) explain that, "When learners are given the opportunity to engage in meaningful activities they are compelled to 'negotiate for meaning,' that is, to express and clarify their intentions, thoughts, opinions, etc., in a way which permits them to arrive at a mutual understanding. This is especially true when the learners are working together to accomplish a particular goal . . . " $p$. 122). Pica (1994) goes on to define negotiation as "modification and restructuring that occurs when learners and their interlocutors anticipate, perceive, or experience difficulties in message comprehensibility" (p.495). Modifications may involve linguistic simplification as well as conversational strategies such as repetition, clarification, and confirmation checks. Long and Robinson's interaction hypothesis (as cited in Blake, 2000) suggests that when meaning is negotiated, there is increased comprehensibility of input and learners tend to focus on salient linguistic features. Awareness of these language forms and structures is seen as beneficial to SLA.

Other interactionist theorists define the role of interaction in SLA by applying Vygotsky's socio-cultural theory of human mental processing (Lightbrown and Spada, 1999). They hypothesize that second language learners may gain proficiency from interacting with more advanced speakers of the language, for example, teachers and peers, as more proficient speakers tend to use scaffolding structures such as modelling, repetition, and linguistic simplification, believed to provide support to learners, thus enabling them to function within their zones of proximal development (Vygotsky, 1962).

The use of language games is therefore not a stand-alone method in ELT; it is a means of creating an environment using a game-like activity that encourages and supports practice and natural use of the language input that has recently taken place in the classroom.

\section{Language Games in ELT Practice}

Language games may not have received the interest and respect it deserves simply because the activities are generally seen more as ways to liven up the class rather than for real learning. Nguyen Thi Thanh Huyen and Khuat Thi Thu Nga (2003) are among researchers that claim that although games are seen as a time-filling activity in most English classrooms, they are not just for fun because they have an effect on teaching and learning. Ahmed Awad Amin Mahmoud and Ziyad Ahmed Tanni (2014) studied the role of language games on pupils' attitudes towards learning English. Most of the teachers of English for the Palestinian young children aged 6-10 years (grades 1- 4) in the schools of Jenin Refugee Camp, Ya'bad, Araba, and Rommana acknowledged that using games affected the pupils' attitudes towards learning English. They did not perceive of using games just for fun but saw them as serving many educational purposes such as developing creative thinking, critical thinking, problem solving, role playing and collaborative work.

There is much in the ELT literature that promotes the use of games. Language games encourage interaction among pupils; when children play language games in small groups, they engage in cooperative learning activities that encourage them to talk freely and offer natural opportunities for social interaction. Learning is more effective when school children have the opportunity to participate freely in discussing ideas and sharing information. Fromme (2003) concurs 
with McFarlane and Sakellariou (2002) in promoting the use of games from different points of view. Games can lower anxiety, thus facilitating acquisition of the second language. As they are highly motivating and entertaining they can draw out shy or timid pupils by providing ample opportunity to express their opinions and feelings.

Games can help the teacher create useful and meaningful contexts for learning new vocabulary (Cameron, 2001, in Seda, 2010). Using games in the teaching and learning of vocabulary is particularly effective because in a fun situation, learning is less stressful for children and increases their' motivation too. According to Wright et al. (1996:1) games help and encourage many learners to sustain their interest. Mazidatuz Zahro et al. (2013) used guessing games in the form of crossword puzzles and riddles to examine the effects of these games on the vocabulary achievement of eight-year old pupils in Balung, Indonesia. The findings showed that the use of guessing games had a clear positive effect on the pupils' vocabulary achievement. Nguyen Thi Thanh Huyen and Khuat Thi Thu Nga (2003) also acknowledged that games were effective in helping their pupils improve their vocabulary building skills.

By taking part in the variety of games designed to integrate all the language skills, children expand their language skills in a natural and holistic manner. Practising any one particular skill promotes development in the other skills too, because they read when they write, and they listen when they are talking with someone. This is significant as connections between abstract and concrete concepts are best accomplished when all language processes-reading, writing, listening, and speaking —are incorporated during practice and application (http://www.misd.net/bilingual/ell.pdf). Most importantly, games enable pupils to acquire new experiences within a foreign language and add a diversion to the regular classroom activities, thus creating a relaxed atmosphere which makes it easier and faster to learn, and to remember.

Ersoz (2000) offers some advice on how to choose games in teaching and learning language. Firstly, games should be regarded as supplementary activities. The whole syllabus should not be based on games only - not even for young learners. Secondly, when choosing a game, the teacher should be careful to find an appropriate one for the class in terms of language and type of participation. Thirdly, once the game has begun, the teacher should not interrupt to correct mistakes in language use. Fourthly, the teacher should not compel an individual to participate. Some learners may not want to participate due to personal reasons and forcing children to participate usually does not have successful results. Fifth, a game which looks wonderful on paper may not work in an actual classroom setting. If it is tiring or boring, it should be stopped. Sixthly, instructions must be given clearly. Unless the learners know what he is expected to do and how to do it, the aim cannot be achieved, and the game cannot be played. Well- chosen games are valuable, highly motivating, amusing, challenging and they encourage cooperation as they give students a break and at the same time allow students to practise language skills.

\section{Methodology}

This study aimed to survey the perceptions of young learners of the use of language games in learning English. As it was a pilot study, it was decided that a quantitative approach would be appropriate for the research design. Purposive sampling was used in selecting 112 Year 3 learners from a selected rural school in Mantin, Negeri Sembilan, Malaysia. This sample was chosen because they were in level I of the Primary School Standard Curriculum. Thirty English Language Studies (ELS) undergraduates from a public university worked in groups of four to design language games for the learners. While the task of designing language games was a graded project on the ELS programme, the use of the games in the selected school was part of a project envisaged to promote English literacy among rural children. The language games were aimed at injecting fun into the learning of English and were expected to motivate and develop confidence among pupils, and shy learners in particular would benefit from the opportunity to express their opinions and feelings in a stress-free, non-threatening environment (Fromme, 2003).

The instrument used for gathering data was a self-report questionnaire to get feedback from pupils about their experience of playing the game. The 10- item questionnaire was designed using a 3-point Likert scale (Agree, Unsure and Disagree) appropriate to the intellectual ability of young learners. In addition, it was written in simple and straightforward Malay to ensure it was clear and easily understood by the young learners. Items 1-7 required students to indicate their perceptions of learning English using games while items 8-10 asked about their perception of the roles of the student facilitators.

The questionnaire was administered after they had participated in a session of language games. The language games were created and prepared by the ELS undergraduates who also served as student facilitators in introducing the games and managing the young learners as they played the games.

The ELS undergraduates had worked in small groups of four to discuss the types of language games they considered suitable based on the pupils' age. These ELS students themselves gained an opportunity not only for social interaction which promotes language development, but more importantly the project afforded them a practical opportunity 
to apply the theories of language learning in designing the activities. The activities had to meet the language and learning needs of the target group and had to stimulate high levels of student engagement, providing them with opportunities to use English in meaningful ways.

They also developed useful soft skills from working as a team: learning to express their ideas, to accept criticism, and to argue their case. In the end, they had to agree unanimously on a language game and therefore had to solve problems and issues related to their projects by engaging in discussion in a sensible and fair manner. It also required them to draw upon their own experience as ESL/EFL learners as well as explore their own creativity.

Besides discussing and creating the language games, the ELS students had to report their progress in writing and also orally to the lecturer. They had to record their work of designing a language game, giving a clear explanation of the game and instructions for using the game. They also needed to practise good management skills as this was not the only task they had to attend to. Thus, the project of devising the language games actually afforded learning opportunities to be creative and to work as a team.

On the day of the activity, the school children were assigned to eight small groups (15-16 children in a group), each group to a game. Each game was monitored and facilitated by the group of four to five ELS students who had created the game. When a group finished one game, it would move on to the next and this went on till every group had played all eight games. Thus, all the school children involved had the opportunity to play all the eight language games created by the ELS students. The activities were held in the hall from 9 a.m. to 1 p.m. No other classes were held for year 3 on the particular day. Food and drinks were provided for the students. By the end of the day, there was a handing-over ceremony of the games by the leader of each ELS group members to the headmaster of the school. Each of the 112 schoolchildren received a Certificate of Participation signed by the Head of the ELS Programme.

The language games helped pupils overcome their apprehensiveness about learning English. When they participated in the games, it could be observed that they became less conscious about using English as they were immersed in the games and having fun. The project seemed to have benefited not only the school children, but also the university students who had learned a lot on their own from designing and facilitating the language games/activities. Their own excitement about the project and enthusiasm in working with the school children was contagious, as evident from the positive feedback from the pupils about their experience. The comments from the headmaster and the English language teachers involved were very positive as they could see that the school children had so much fun and were so enthusiastic in using English, being so immersed in the activities that they practically forgot their former apprehension about making mistakes. These can be seen from the pictures taken during the activities (See Appendix A). The most important outcome was therefore the positive experience of accomplishment in their language learning experience, for, as the saying goes, success breeds success.

\section{The Young Learners' Perceptions}

The data was analysed descriptively using frequency and percentages. On the whole, the results indicate that the pupils had positive perceptions learning English using games. The great majority of the respondents (93.75\%) agreed with the first statement "I was very happy when the teacher told us that learning English through language games would be held on that day". $4.46 \%$ felt unsure and $1.78 \%$ did not agree with the statement. When the university students arrived at the school on that day, the teachers told them that 3 weeks prior to the event day itself, the students had been excited and looking forward to experience learning English using games.

In responding to a question about their prior experience of playing language games in English, $51.78 \%$ agreed with the second statement "I have played language games in English before" while 34.82\% were unsure and 13.39\% did not agree. These responses indicate that only about half of them had played language games before. Being situated in a rural area, not all the school children would have had language games in English. Besides, the schools do not have enough funding to provide them with such opportunities.

When asked to respond about their feelings using English in playing language games, 65.18\% indicated that they did not feel shy to use English, as in statement 3 "I am not shy to play language games using English language". However, $23.21 \%$ indicated they were unsure while $11.61 \%$ did not agree with the statement. This lends support to Fromme's (2003) finding that language games lower learners' anxiety, motivate and give confidence and also provide shy learners with the opportunity to express their opinions and feelings.

Using games to learn English was a source of enjoyment to the pupils, supporting Ersoz's (2000) findings that language games are motivating, amusing and challenging. The evidence is in the responses given by the learners; 98.21\% agreed with statement 4, "I feel happy and enjoyed myself playing language games using English language". $1.79 \%$ were unsure and only $0.89 \%$ did not agree with the statement. 
Almost all the respondents felt that the activity taught them more about English. This can be seen when $97.32 \%$ of them agreed with statement 5, "playing the games today taught me a lot about English language". Only 1.79\% were unsure of the statement and $0.89 \%$ did not agree. Again, this supports the results of Ersoz's (2000) study which found that language games encourage cooperation as they provide opportunities to practise language skills.

With regard to acquisition of new vocabulary, the findings reveal that $91.96 \%$ of the respondents agreed that they have acquired new vocabulary while $6.25 \%$ were unsure and $1.79 \%$ did not agree. To a certain extent, the findings concur with Mazidatuz Zahro et al.'s (2013) study which found that using language games affected the students' vocabulary achievement positively.

Most of the students involved reported feeling more confident in using English after playing the language games; a total of $72.32 \%$ agreed with statement 7, "I am more confident to use English language after playing the language games". However $20.54 \%$ were unsure and $7.14 \%$ did not agree that they had gained more confidence in using the language. According to Vygotsky's (1962) socio-cultural theory, when learners interact with more advanced speakers (i.e. student facilitators) of the language, it provides them with scaffolding structures that enable them to function within their zones of proximal development (Lightbrown \& Spada, 1999). Considering that there was limited time in interacting with the facilitators, this response seems honest, and does not detract from the overall positive feedback. In fact, this highlights the need to sustain such efforts, as a one-off effort admittedly may not have a significant effect on pupils's confidence in learning English.

The young learners were guided by the student facilitators rather than their own teachers as part of the effort at creating a non-threatening context that this approach promotes. The findings reveal that $93.75 \%$ agreed that "The facilitators from the university were very dedicated and committed when handling the language games with me", while 4.46\% and 1.79\% responded as "unsure" and "did not agree" respectively. In line with this, Lightbrown and Spada (1999) posited that young learners are able to function within their zones of proximal development during their interaction with more advanced speakers (i.e. student facilitators) when they engage in these language games, expressing and clarifying their intentions, thoughts, and opinions in this non-threatening context.

As for their perception of the facilitators' treatment of all the school children, the majority (91.07\%) of the respondents agreed with they received equal attention and treatment. Finally, almost all (93.75\%) of the learners who took part in the language games would like to have the opportunity to do the activity again in the future. Playing language games was a new experience and a happy diversion from the regular classroom activities (Fromme, 2003).

\section{Conclusion}

The feedback from the pupils provides adequate evidence for the positive impact of using language games in teaching English. As a pilot project, there are some aspects that need fine-tuning and rethinking. For example, since this was a one-day event of language games, the fun factor was particularly salient and time was not a constraining factor; however, in the daily class, teachers have to plan their lessons to allow for some time to have a game played as reinforcement of particular learning points. Also, it must be remembered that the ELS undergraduates had designed eight games after a great deal of time and effort, so teachers may wonder if their schedule would allow them any time to create language games. There are of course answers to such reservations and doubt about the practicality of using language games. There are games galore available in print and in online ELT sites, and each game need not take up a lot of time. In fact a game may be repeated and if found to be a source of fun, the pupils themselves may play on their own whenever there is some time available.

There are plans for the pilot project to become a regular part of the English curriculum for the particular school that hosted it. This is indeed promising, and if that is established, there are many possibilities of expanding this effort and replicating it in other rural schools. It would also then become necessary to offer some kind of training to teachers who are unfamiliar with the concept of games in language learning, and perhaps in the process, afford a practical way of demonstrating how a learner-centred classroom should be.

Given the enthusiasm of the school authorities and the teachers, and the eagerness of the young learners, this pilot study is likely to proceed to develop into a full-fledged programme to supplement language classes, and become an initiative for the community literacy effort that first gave birth to this idea of using language games in SL learning.

\section{References}

Ahmed Awad Amin Mahmoud \& Ziyad Ahmed Tanni. (2014). Using games to promote students' motivation towards learning English. AlQuds Open University Journal for Educational \& Psychological Research \& Studies, 2(5), 11-33. 
Blake, R. (2000). Computer mediated communication: A window on L2 Spanish interlanguage. Language Learning and Technology, $4(1), 120-136$.

Cameron, L. (2001) Teaching languages to young learners. Cambridge, England: Cambridge University Press.

Ersoz, A. (2000). Six games for EFL/ESL classroom. The Internet TESL Journal, 6(6). Retrieved from http:/liteslj.org/Lessons/ErsozGames.html 8

Fromme, J. (2003). Computer games as a part of children's culture. Game Studies, 3(1). Retrieved from http://gamestudies.org/0301/fromme

Huyen, N. T. T. \& Thu-Nga K.T. (2003). Learning vocabulary through games. Asian EFL Journal. Retrieved from http://www.asian-efljournal.com/dec_03_vn.pdf

Krashen, S. (1985). The input hypothesis. Beverly Hills, CA.: Laredo Publishing Company.

Krashen, S. (1994). The input hypothesis and its rivals. In N. Ellis (Ed.) Implicit and explicit learning of languages. (pp. 45-77). London, England: Academic Press.

Krashen, S. (1996). Under attack: The case against bilingual education. Culver City, CA: Language Education Associates.

Kurikulum Standard Prasekolah Kebangsaan (KSPD) \& Kurikulum Standard Sekolah Rendah (KSSR). Retrieved from http://www.slideshare.net/Fadzliaton/transformasi-kurikulum-kssr 7171559?utm_source=slideshow02\&utm_medium=ssemail\&utm_campaign=share_slideshow_loggedout)

Lightbrown, P. M. \& Spada, N. (1999). How languages are learned. Oxford, England: Oxford University Press.

Long, M. H. (1985). Input and second language acquisition theory. In S. Gass and C. Madden (Eds.) Input in second language acquisition (pp. 377-393). Rowley, MA: Newbury House.

Making content comprehensible for English language learners-SIOP Model SHELTERED INSTRUCTION- for Academic Achievement. Retrieved from http://www.misd.net/bilingual/ell.pdf

Mansoor Fahim \& Somayyeh Sabah. (2012). An ecological analysis of the role of role-play games as affordances in Iranian EFL preuniversity students' vocabulary learning. Theory and Practice in Language Studies, Vol 2 (6), 1276-1284.

Mazidatuz Zahro, Bambang Suharjito \& Sudarsono. (2013). The effect of guessing games on the eight year students' vocabulary achievement at SMPN 03 Balung Jember in the 2012/2013 academic year. Pancaran, Vol. 2(3), 115-124.

McFarlane, A \& Sakellariou, S. (2002). The role of ICT in science education. Cambridge Journal of Education 32(2), 219-232.

Normazidah Che Musa, Koo Yew Lie \& Hazita Azman. (2012). Exploring English language learning and teaching in Malaysia. GEMA Online TM Journal of Language Studies 12(1), 35-51.

Official Website Ministry of Education Malaysia. Retrieved from http://moe.gov.my/en/soalan-lazim-view?id=146\&cat=30 \&keyword=\&page $=1 \&$

Pica, T. (1996). Second language learning through interaction: Multiple perspectives. Working Papers in Educational Linguistics, 12(1), $1-22$.

Pica, T. (1994). Research on negotiation: What does it reveal about second language learning conditions, processes, and outcomes? Language Learning, 44(3), 493-527.

Samuel, R., \& Zaitun Bakar. (2008). The effectiveness of "VELT" in promoting English language communication skills: A case study in Malaysia, International Journal of Education and Development Using Information and Communication Technology, 4(3), 109-126.

Seda, A. (2010). Using game in improving vocabulary achievement at the third year students of SD Negeri 04 Baruga. Retrieved from http://amilseda12.blogspot.com/2012/06/normal-0-false-false-false-en-us-x-none.html

Souriyavongsa, T., Sam Rany, Mohamad Jafre Zainol Abidin \& Leong Lai Mei. (2013). Factors causes students low English language learning: A case study in the National University of Laos. International Journal of English Language Education, 1 (1), 179-192.

Swain, M. (1995). Three functions of output in second language learning. In. G. Cook and G. Seidhofer (Eds.) Principles and practices in applied linguistics: Studies in honor of H. G. Widdowson (pp. 125-144). Oxford, England: Oxford University Press.

Vygotsky, L. (1962). Thought and language. Cambridge, MA: MIT Press.

Wright, A., Betteridge, D. \& Buckby, M. (1996). Games for language learning. Cambridge, England: Cambridge University Press. 


\section{Appendix A}
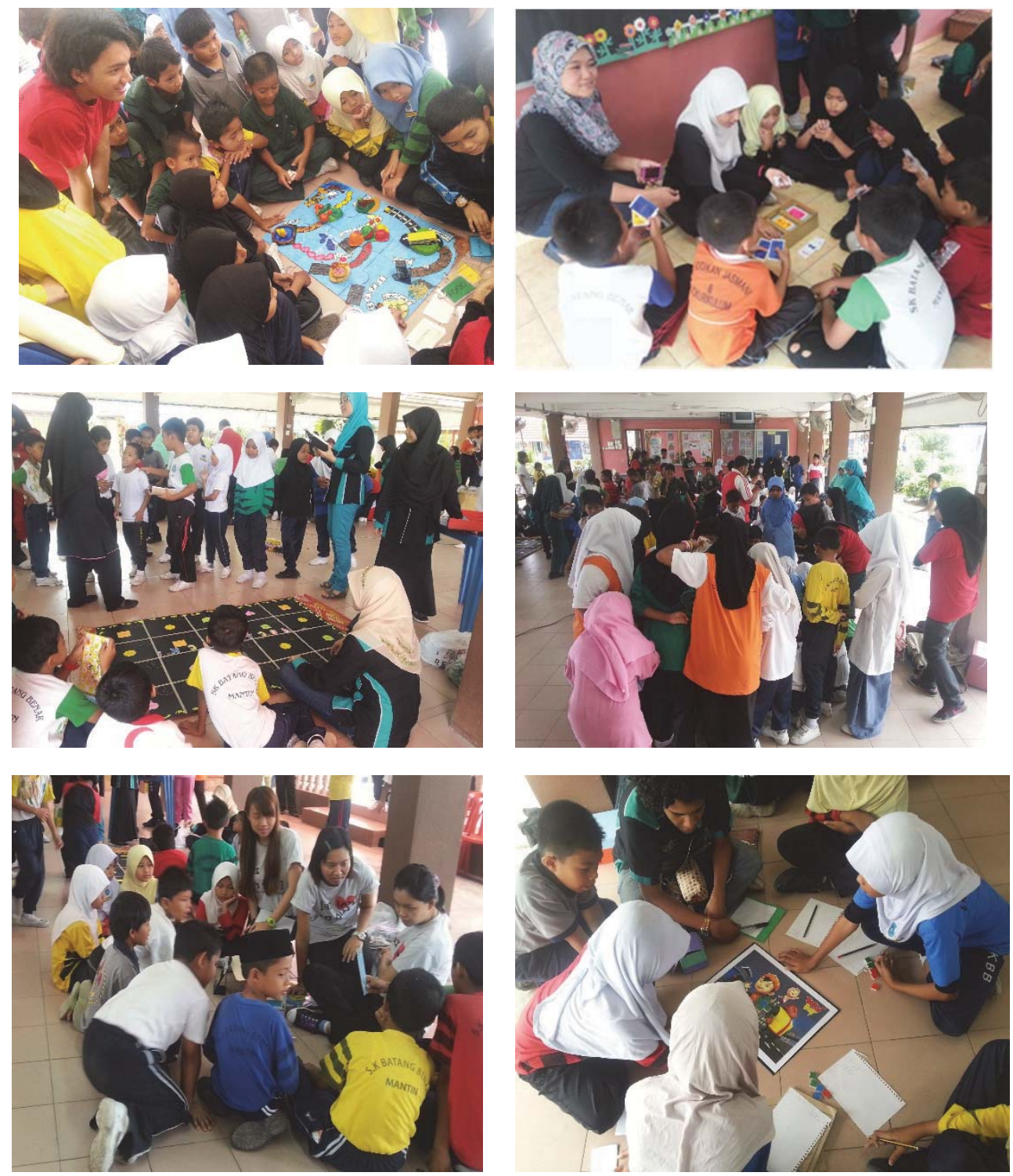